\title{
PENGARUH LINGKUNGAN KERJA, PENGAWASAN, KOMPETENSI DAN MOTIVASI TERHADAP KINERJA DENGAN VARIABEL KOMPENSASI SEBAGAI VARIABEL INTERVENING PADA PEGAWAI DISHUBKOMINFO KOTA TEGAL
}

\author{
Dessi Rosdiana dan Dewi Indriasih \\ Politeknik Keselatan Transportasi Jalan, dan Universitas Pancasakti Tegal \\ Dessiros12@gmail.com
}

\begin{abstract}
The success of an organization in achieving its objectives, cannot be separated from the human resources factor. This is because human resources is a key factor to mobilize other resources that exist within an institution. To realize these goals can be achieved by improving the performance of human resources with the many factors that influence it. The purpose of this research is; 1) to analyze empirically significant influence Work Environment, Supervision, Competency, Motivation, Employee Compensation Dishubkominfo to Tegal. 2) To analyze empirically significant influence Work Environment, supervision, competence, motivation, the employee's performance Dishubkominfo Tegal. 3) To determine empirically significant influence as an intervening variable compensation to employee performance Dishubkominfo Tegal. This type of research is explanatory research (explanation) using a quantitative approach. The location of this research is Dishubkominfo Office of Tegal. With the object of study include: 1) Work Environment, 2) Supervision, 3) Competence, 4) Motivation, 5) Performance and Compensation office clerk Dishubkominfo Tegal. Office workers Dishubkominfo population numbered 204 people with various strata covering court clerks, staff and leaders in the ranks Dishubkominfo Office Tegal as the sample is equal to 135 Employees who are civil servants and non-civil servants. The results showed that: 1) Work Environment, competence significantly influence employee compensation Dishubkominfo Tegal is proven. 2) Monitoring Motivation significantly influence employee compensation Dishubkominfo Tegal is not proven. 3) Working Environment Monitoring significant effect on employee performance Dishubkominfo Tegal is proven. 4) Competence Motivation significant effect on employee performance Dishubkominfo Tegal is proven. 5) Compensation as an intervening variable is a significant positive influence between work environment, supervision, competence and motivation to employee performance Dishubkominfo Tegal is proven.
\end{abstract}

Keywords: Work Environment, Supervision, Competency, Motivation, Performance, Compensation.

\section{PENDAHULUAN}

Sumber daya manusia yang kompeten akan memberikan kontribusi yang sangat besar, karena disinilah akan ditentukan perubahan-perubahan terhadap hasilnya baik secara kuantitatif maupun kualitas. Strategi pengembangan SDM yang pada saat ini mengacu pada Sasaan Kinerja Pegawai (SKP) sebagai dasar penilaian kinerja diharapkan mampu mengevaluasi kinerja dan menilai seberapa jauh pencapaian kinerja Kantor Dishubkominfo Kota Tegal. 
Dalam penelitian Prasetya (2015:6) terdapat Beberapa hal yang berhubungan dengan kinerja pegawai diantaranya adalah 1) lingkungan kerja, 2) kompensasi yang diperoleh Pegawai atas apa yang telah dikerjakan, dan 3) pengawasan sebagai fungsi manajemen untuk mengevaluasi pencapaian. Lingkungan kerja dalam suatu organisasi mempunyai peranan penting untuk kelancaran proses kegiatan, menurut Nitisemito, et.al. (Fathonah, 2011:6) lingkungan kerja adalah segala sesuatu yang ada di lingkungan pekerjaan yang dapat mempengaruhi dirinya dalam menjalankan tugas yang dibebankan.

Kompensasi menurut Malayu S.P. Hasibuan (2012:118) adalah semua pendapatan yang diterima Pegawai yang berbentuk uang, barang langsung atau tidak langsung yang merupakan bentuk biaya yang harus dikeluarkan perusahaan dengan harapan memperoleh imbalan berupa prestasi kerja dari Pegawai. Tujuan pemberian kompensasi antara lain adalah sebagai ikatan kerja sama, kepuasan kerja, pengadaan efektif, motivasi, stabilitas Pegawai, disiplin, serta pengaruh serikat buruh dan pemerintah. Hal ini senada dengan Dessler (2009:2), yang menyatakan bahwa pengawasan (Controlling) merupakan penyusunan standar seperti kuota penjualan, standar kualitas, atau level produksi; pemeriksaan untuk mengkaji prestasi kerja aktual dibandingkan dengan standar yang telah ditetapkan; mengadakan tindakan korektif yang diperlukan. Hasil pekerjaan Pegawai dapat diketahui melalui laporan pengawasan tertulis baik laporan rutin maupun laporan khusus. Penelitian yang telah dilakukan oleh Puspitasari, et al.
(2015) pada hasil penelitian menunjukkan bahwa motivasi dan lingkungan kerja secara simultan berpengaruh nyata terhadap kinerja Pegawai. Motivasi kerja menjadi pemicu Pegawai agar Pegawai menghasilkan kinerja yang baik tanpa ada paksaan, sebaliknya, kurangnya motivasi dalam bekerja dapat mempengaruhi kinerja Pegawai meskipun Pegawai tersebut memiliki potensi kerja yang baik.

Sebagai instansi pemerintahan yang bergerak di bidang pelayanan masyarakat, tentu memerlukan sistem pengawasan yang matang dan cermat guna mencegah terjadinya penyelewengan dan kesalahan yang dapat merugikan pemerintah. Di sisi lain, adanya lingkungan kerja yang kompleks turut mempengaruhi kinerja pegawai Dishubkominfo Tegal. Hal ini mendorong penulis untuk meneliti sejauh mana pengaruh lingkungan kerja dan adanya pelaksanaan pengawasan yang dilaksanakan oleh instansi pemerintahan Dishubkominfo Tegal terhadap kinerja pegawainya.

\section{METODE PENELITIAN}

Peneliti menggunakan jenis penelitian explanatory (penjelasan). Jenis penelitian ini merupakan penelitian yang digunakan untuk menguji hipotesis tentang adanya hubungan variabelvariabel (hubungan sebab akibat) sebagai topik penelitian dengan menggunakan pendekatan kuantitatif. Dari deskripsi di atas dapat digambarkan skema korelasi antar variabel sebagai berikut: 


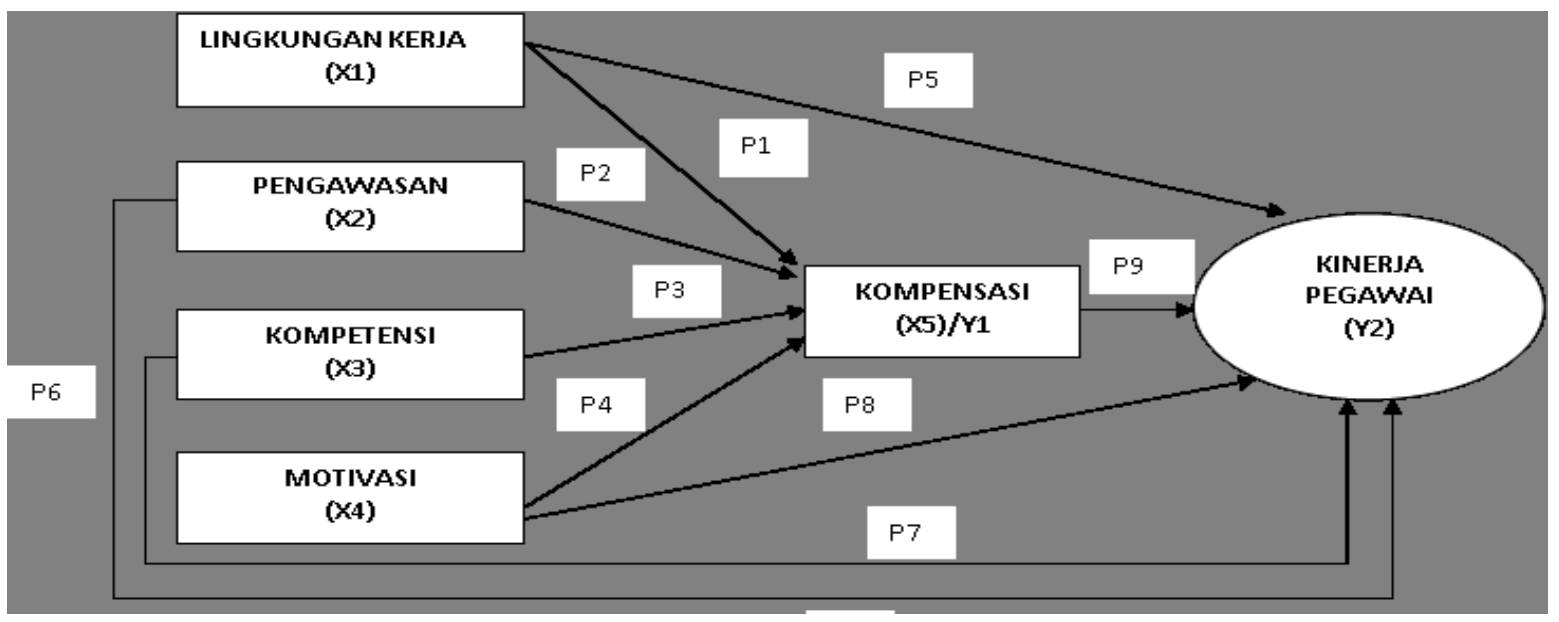

Gambar 1: Kerangka Konsep Penelitian. Sumber (Sarwono, 2007)

Keterangan:

1. Variabel Independen : Lingkungan Kerja, Pengawasan, Kompetensi dan Motivasi

2. Variabel Dependen : Kinerja pegawai

3. Variabel Intervening : Kompensasi pegawai

Lokasi dalam penelitian ini adalah Kantor Dishubkominfo Kota Tegal. Adapun Obyek penelitian dalam tulisan ini meliputi: 1) Lingkungan Kerja, 2) Pengawasan, 3) Kompetensi, 4) Motivasi, 5) Kinerja, dan Kompensasi Pegawai kantor Dishubkominfo Kota Tegal. populasi Pegawai kantor Dishubkominfo berjumlah 204 orang dengan berbagai strata meliputi Pegawai lapangan, staf dan pimpinan di jajaran Kantor Dishubkominfo Kota Tegal sebagai sampel dalam penelitian yaitu sebesar 135orang Pegawai yang berstatus PNS dan non PNS.

Teknik pengumpulan data dilakukan dengan cara Kuisioner. Kuesioner merupakan metode pengumpulan data dengan menggunakan instrument penilaian kuesioner atau angket. Pertanyaan yang diberikan pada kuesioner ini adalah pertanyaan menyangkut fakta dan pendapat responden, sedangkan kuesioner yang digunakan pada penelitian ini adalah kuesioner tertutup, dimana responden diminta menjawab pertanyaan dan menjawab dengan memilih dari sejumlah alternatif.
Instrumen ini digunakan untuk menjaring data mengenai Lingkungan Kerja, Pengawasan, Kompensasi, dan Kinerja Pegawai yang menjadi variabel penelitian. Ditinjau dari data dan jenis analisisnya, penelitian ini termasuk penelitian sampel dalam kategori data kuantitiatif. Data kuantitatif diperoleh dengan menggunakan sakala Likert (Sugiyono, 2001:14).

\section{HASIL PENELITIAN DAN PEMBAHASAN}

Pengujian validitas item-item pertanyaan variabel menggunakan teknik one shot method yaitu dengan membandingkan $\mathrm{r}$ hitung dengan $\mathrm{r}$ tabel 0,176 .

1. Validitas Item Pertanyaan Untuk Variabel Kinerja(Y)

Nilai terendah $\mathrm{r}$ item $.359>0,176$ menunjukkan bahwa 10 item pertanyaan semua valid sehingga dapat digunakan sebagai intrumen dalam penelitian ini.

2. Validitas item pertanyaan untuk variabel Lingkungan Kerja $\left(\mathrm{X}_{2}\right)$ 
Nilai terendah ritem $-.223>0,176$ menunjukkan bahwa 10 dari 12 item pertanyaan valid sehingga dapat digunakan sebagai intrumen dalam penelitian ini.

3. Validitas item pertanyaan untuk variabel Pengawasan $\left(\mathrm{X}_{2}\right)$

Nilai terendah $\mathrm{r}$ item .015>0,176 menunjukkan bahwa 10dari 14item pertanyaan valid sehingga dapat digunakan sebagai intrumen dalam penelitian ini.

4. Validitas item pertanyaan untuk variabel Kompetensi $\left(\mathrm{X}_{3}\right)$

Nilai terendah $\mathrm{r}$ item .177> 0,176 menunjukkan bahwa 8item pertanyaan valid sehingga dapat digunakan sebagai intrumen dalam penelitian ini.
5. Validitas item pertanyaan untuk variabel Motivasi $\left(\mathrm{X}_{4}\right)$

Nilai terendah $\mathrm{r}$ item .295>0,176 menunjukkan bahwa 8 item pertanyaan valid sehingga dapat digunakan sebagai intrumen dalam penelitian ini.

6. Validitas Item Pertanyaan Untuk Variabel Kompensasi (X5/Y1)

Nilai terendah $\mathrm{r}$ item .253>0,176 menunjukkan bahwa 10item pertanyaan valid sehingga dapat digunakan sebagai intrumen dalam penelitian ini.

Hasil uji reliabilitas dengan menggunakan bantuan program SPSS for Windows V.19 dapat dilihat dalam tabel di bawah ini :

Uji Reliabilitas

\begin{tabular}{|c|c|c|c|}
\hline Variabel & $\begin{array}{c}\text { Cronbach's } \\
\text { Alpha }\end{array}$ & Kriteria & Keterangan \\
\hline Kinerja (Y2) & 0,793 & \multirow{6}{*}{$\begin{array}{c}\text { Cronbach's } \\
\text { Alpa }>0.6 \\
\text { maka } \\
\text { dinyatakan } \\
\text { reliabel }\end{array}$} & Reliabel \\
\hline Lingkungan Kerja (X1) & 0,717 & & Reliabel \\
\hline Pengawasan (X2) & 0,787 & & Reliabel \\
\hline Kompetensi (X3) & 0,660 & & Reliabel \\
\hline Motivasi (X4) & 0,654 & & Reliabel \\
\hline Kompensasi (X5/Y1) & 0,788 & & Reliabel \\
\hline
\end{tabular}

Sumber : data primer diolah

Berdasarkan tabel di atas dapat diketahui bahwa nilai Cronbach's Alpha dari masing-masing variabel menunjukkan bahwa nilai $>0,60$ sehingga data yang dikumpulkan dinyatakan reliabel, sehingga pernyataan dapat dipergunakan.

\section{Analisis Regresi Linier}

Analisis ini digunakan untuk mengetahui pengaruh dari variabel terikat dengan menggunakan 2 (dua) persamaan. Hasil 2 persamaan tersebut diuraikan sebagai berikut: 
Uji Regresi Jalur Persamaan 1

Coefficients $^{\mathrm{a}}$

\begin{tabular}{|c|c|c|c|c|c|c|}
\hline & \multirow[t]{2}{*}{ Model } & \multicolumn{2}{|c|}{ Unstandardized Coefficients } & $\begin{array}{l}\text { Standardized } \\
\text { Coefficients }\end{array}$ & \multirow[t]{2}{*}{$t$} & \multirow[t]{2}{*}{ Sig. } \\
\hline & & $B$ & Std. Error & Beta & & \\
\hline \multirow{5}{*}{1} & (Constant) & 4.918 & 5.205 & & .945 & .347 \\
\hline & Lingkungan Kerja & .632 & .062 & .648 & 10.203 & .000 \\
\hline & Pengawasan & .008 & .097 & .005 & .083 & .934 \\
\hline & Kompetensi & .354 & .094 & .238 & 3.771 & .000 \\
\hline & Motivasi & .133 & .092 & .091 & 1.450 & .150 \\
\hline
\end{tabular}

a. Dependent Variable: Kompensasi

Persamaan regresi 1 sebagai berikut:

$\mathrm{Y}_{1}=0,632 \mathrm{X}_{1}+0,008 \mathrm{X}_{2}+0,354 \mathrm{X}_{3}+0,113 \mathrm{X}_{4}+\epsilon$

Sig $(0,000) \quad(0,934)^{* *}(0,000)^{* *}(0,150)$

Uji Regresi Jalur Persamaan 2

Coefficients $^{\mathrm{a}}$

\begin{tabular}{|l|r|r|r|r|r|}
\hline \multirow{2}{*}{ Model } & \multicolumn{2}{|c|}{$\begin{array}{c}\text { Unstandardized } \\
\text { Coefficients }\end{array}$} & $\begin{array}{c}\text { Standardized } \\
\text { Coefficients }\end{array}$ & \multirow{2}{*}{$\mathrm{t}$} & \multirow{2}{*}{ Sig. } \\
\cline { 2 - 5 } & \multicolumn{1}{|c|}{$\mathrm{B}$} & Std. Error & Beta & & \\
\hline \multirow{2}{*}{ (Constant) } & -2.675 & 3.377 & & -.792 & .430 \\
Lingkungan Kerja & .308 & .054 & .325 & 5.681 & .000 \\
Pengawasan & .034 & .063 & .022 & .544 & .588 \\
Kompetensi & .133 & .064 & .092 & 2.071 & .040 \\
Motivasi & .150 & .060 & .106 & 2.515 & .013 \\
Kompensasi & .584 & .058 & .602 & 10.102 & .000 \\
\hline
\end{tabular}

a. Dependent Variable: Kinerja

Persamaan regresi 2 sebagai berikut:

$\mathrm{Y}_{2}=0,308 \mathrm{X}_{1}+0,034 \mathrm{X}_{2}+0,133 \mathrm{X}_{3}+0,150 \mathrm{X}_{4}+0,584 \mathrm{X}_{5}+\epsilon$

Sig $(0,000)(0,588)^{* *}(0,040)^{* *}(0,013)^{* *}(0,000)^{* *}$

Penelitian ini digunakan untuk mengetahui hipotesis diterima atau ditolak yaitu dengan membandingkan nilai signifikansi $\mathrm{t}$ dengan taraf yang digunakan. Pengujian dalam penelitian ini menggunakan taraf signifikansi 0,05 $(\alpha=5 \%)$. Jika nilai signifikansi $\mathrm{t}<0,05$

maka Ho ditolak dan Ha diterima, sedangkan jika nilai signifikansi $>0,05$ maka Ho diterima dan Ha ditolak. Hasil uji t pada persamaan 1 dan persamaan 2 selengkapnya dapat dilihat pada tabel di bawah ini :

\begin{tabular}{|l|l|l|l|l|}
\hline \multicolumn{1}{|c|}{ Pers } & \multicolumn{1}{|c|}{ Variabel } & \multicolumn{1}{c|}{ t } & \multicolumn{1}{c|}{ Sig } & \multicolumn{1}{c|}{ Keterangan } \\
\hline I & Lingkungan Kerja $\left(\mathrm{X}_{1}\right)$ & 10.203 & .000 & Signifikan \\
\hline & Pengawasan $\left(\mathrm{X}_{2}\right)$ & .083 & .934 & Tidak Signifikan \\
\hline & Kompetensi $\left(\mathrm{X}_{3}\right)$ & 3.771 & .000 & Signifikan \\
\hline & Motivasi $\left(\mathrm{X}_{4}\right)$ & 1.450 & .150 & Tidak Signifikan \\
\hline II & Lingkungan Kerja $\left(\mathrm{X}_{1}\right)$ & 5.681 & .000 & Signifikan \\
\hline & Pengawasan $\left(\mathrm{X}_{2}\right)$ & .544 & .588 & Tidak Signifikan \\
\hline & Kompetensi $\left(\mathrm{X}_{3}\right)$ & 2.071 & .040 & Signifikan \\
\hline & Motivasi $\left(\mathrm{X}_{4}\right)$ & 2.515 & .013 & Signifikan \\
\hline & Kompensasi $\left(\mathrm{X}_{5}\right)$ & 10.102 & .000 & Signifikan \\
\hline
\end{tabular}

Sumber : data primer diolah 
Berdasarkan pada tabel di atas diketahui beberapa keterangan sebagai berikut:

1. Pengaruh Lingkungan Kerja Terhadap Kompensasi

Hasil uji $t$ persamaan 1 bahwa variabel Lingkungan Kerja terhadap kompensasi kerja diperoleh nilai signifikansi sebesar $0,000>0,05$, menunjukkan bahwa variabel lingkungan kerja signifikan berpengaruh terhadap kompensasi pegawai Pada kantor Dishubkominfo Kota Tegal.

2. Pengaruh Pengawasan terhadap Kompensasi

Hasil uji $t$ persamaan 1 bahwa variabel pengawasan terhadap kepuasan kerja diperoleh nilai signifikansi sebesar $0,934>0,05$, menunjukkan bahwa variabel pengawasan secara tidak signifikan berpengaruh terhadap kompensasi Pegawai Pada kantor Dishubkominfo Kota Tegal

3. Pengaruh Kompetensi terhadap Kompensasi

Hasil uji t persamaan 1 bahwa variabel kompetensi terhadap kompensasi diperoleh nilai signifikansi sebesar $0,000<0,05$, menunjukkan bahwa variabel kompetensi secara signifikan berpengaruh terhadap kompensasi pegawai Pada kantor Dishubkominfo Kota Tegal

4. Pengaruh Motivasi terhadap Kompensasi

Hasil uji $\mathrm{t}$ persamaan 1 bahwa variabel motivasi terhadap kompensasi diperoleh nilai signifikansi sebesar $0,150>0,05$, menunjukkan bahwa variabel motivasi secara signifikan berpengaruh terhadap kompensasi Pada pegawai Pada kantor Dishubkominfo Kota Tegal

5. Pengaruh Lingkungan Kerja terhadap Kinerja Pegawai

Hasil uji $t$ persamaan 2 bahwa variabel lingkungan kerja terhadap kinerja diperoleh nilai signifikansi sebesar $0,000<0,05$, menunjukkan bahwa variabel lingkungan kerja secara signifikan berpengaruh terhadap kinerja Pada Pegawai kantor Dishubkominfo Kota Tegal

6. Pengaruh Pengawasan terhadap Kinerja Pegawai

Hasil uji $t$ persamaan 2 bahwa variabel pengawasan terhadap kinerja diperoleh nilai signifikansi sebesar $0,588>0,05$, menunjukkan bahwa variabel pengawasan secara tidak signifikan berpengaruh terhadap kinerja Pada Pegawai kantor Dishubkominfo Kota Tegal

7. Pengaruh Kompetensi terhadap kinerja pegawai

Hasil uji $t$ persamaan 2 bahwa variabel Kompetensi terhadap kinerja diperoleh nilai signifikansi sebesar $0,040<0,05$, menunjukkan bahwa variabel kompetensi secara signifikan berpengaruh terhadap kinerja Pada Pegawai kantor Dishubkominfo Kota Tegal

8. Pengaruh Motivasi terhadap Kinerja Pegawai

Hasil uji $t$ persamaan 2 bahwa variabel motivasi terhadap kinerja diperoleh nilai signifikansi sebesar $0,013<0,05$, menunjukkan bahwa variabel motivasi secara signifikan berpengaruh terhadap kinerja Pada Pegawai kantor Dishubkominfo Kota Tegal

9. Pengaruh Kompensasi terhadap Kinerja Pegawai

Hasil uji $t$ persamaan 2 bahwa variabel kompensasi terhadap kinerja diperoleh nilai signifikansi sebesar $0,000<0,05$, menunjukkan bahwa variabel kompensasi secara signifikan berpengaruh terhadap kinerja Pada Pegawai kantor Dishubkominfo Kota Tegal berikut: 


\section{Hasil uji $\mathrm{F}$ persamaan 1}

ANOVA $^{a}$

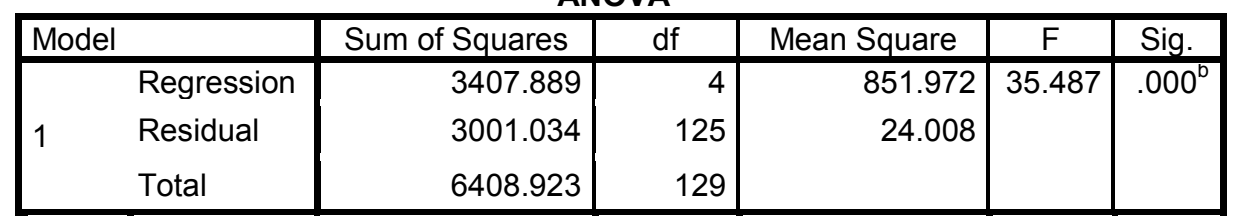

a. Dependent Variable: Kompensasi

b. Predictors: (Constant), Motivasi, Kompetensi, Pengawasan, Lingkungan Kerja

Hasil uji $F$ persamaan ke satu menunjukkan bahwa nilai $\mathrm{F}$ hitung sebesar 35.487 dan memiliki nilai signifikansi sebesar 0,000 berarti secara simultan variabel lingkungan kerja, pengawasan, kompetensi dan motivasi terhadap kompensasi kerja Pada Pegawai kantor Dishubkominfo Kota Tegal.

Hasil uji $\mathrm{F}$ persamaan 2 sebagai berikut:

Hasil uji F persamaan 2

ANOVA $^{a}$

\begin{tabular}{|rl|r|r|r|r|r|}
\hline Model & & Sum of Squares & \multicolumn{1}{c|}{ df } & Mean Square & F & Sig. \\
\hline \multirow{2}{*}{1} & Regression & 4801.441 & 5 & 960.288 & 95.662 & $.000^{\mathrm{b}}$ \\
& Residual & 1244.751 & 124 & 10.038 & & \\
& Total & 6046.192 & 129 & & & \\
\hline
\end{tabular}

a. Dependent Variable: Kinerja

b. Predictors: (Constant), Kompensasi, Pengawasan, Motivasi, Kompetensi, Lingkungan Kerja

Hasil uji $F$ persamaan ke dua menunjukkan bahwa nilai $\mathrm{F}$ hitung sebesar 95,662 dan memiliki nilai signifikansi sebesar 0,000 berarti secara simultan variabel lingkungan kerja, pengawasan, kompetensi, motivasidan kompensasi terhadap kinerja pada pegawai kantor Dishubkominfo Kota Tegal

Analisis jalur memperhitungkan pengaruh langsung dan tidak langsung maupun pengaruh total. Secara lengkap hasil perhitungan analisis jalur dalam penelitian ini dapat dijelaskan secara rinci sebagai berikut:

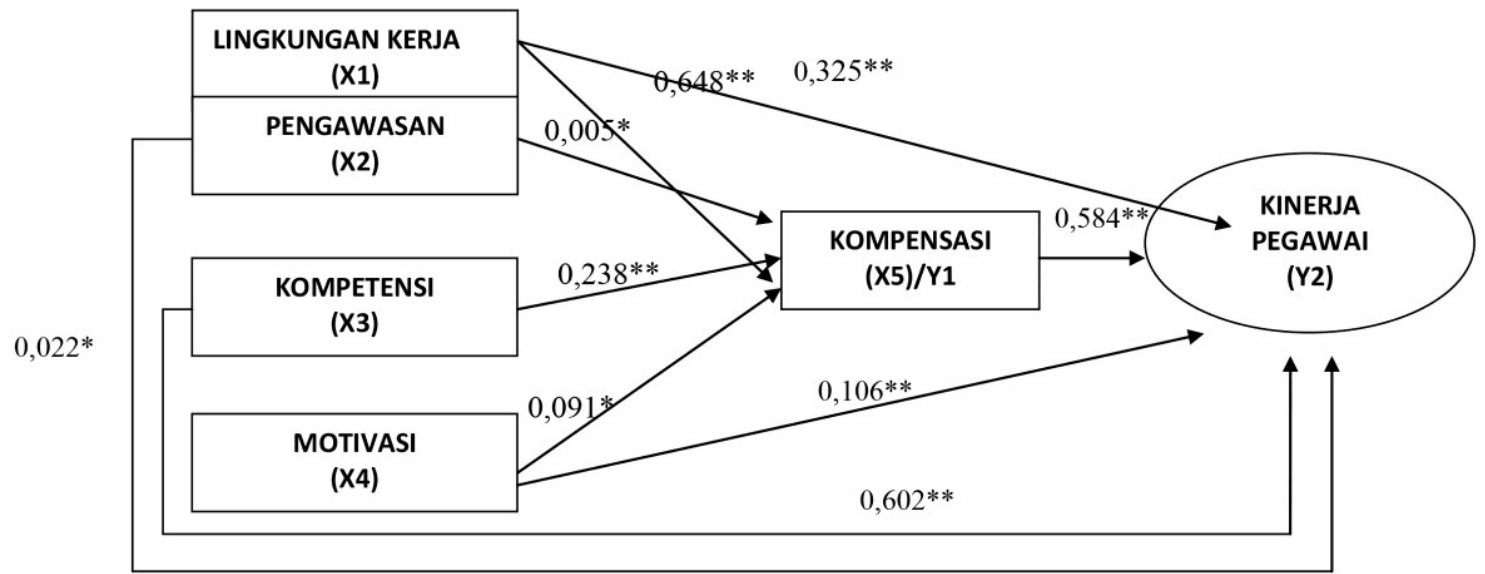




\section{Implikasi Manajerial}

1. Pengaruh Lingkungan Kerja terhadap Kinerja

Hasil penelitian ini membuktikan bahwa lingkungan kerja berpengaruh positif terhadap kinerja pegawai kantor Dishubkominfo Kota Tegal. Berdasarkan hasil analisis perhitungan menggambarkan bahwa kompetensi mempengaruhi kinerja secara langsung.

2. Pengaruh Pengawasan terhadap Kinerja

Hasil penelitian ini membuktikan bahwa pengawasan mempengaruhi kinerja pegawai kantor Dishubkominfo Kota Tegal secara langsung dalam meningkatkan kinerja. Pengawasan sangat penting bagi pegawai, hal ini karena pengawasan merupakan salah satu strategi efektif suatu organisasi dalam upaya mencegah kegiatan non produktif para pegawai.

3. Pengaruh Kompetensi terhadap Kinerja

Dari hasi perhitungan dalam penelitian ini membuktikan bahwa kompetensi berpengaruh terhadap kinerja pegawai kantor Dishubkominfo Kota Tegal secara langsung sehingga dalam meningkatkan kinerja. Kompetensi perlu melewati variabel intervening kompensasi.

4. Pengaruh Motivasi terhadap Kinerja

Dari hasi perhitungan dalam penelitian ini membuktikan bahwa motivasi berpengaruh terhadap kinerja pegawai kantor Dishubkominfo Kota Tegal. Pada sebuah organisasi perusahaan atau pemerintahan, kesuksesan atau kegagalan dalam pelaksanaan tugas dan penyelenggaraan, dipengaruhi motivasi kerja yang dimiliki oleh pagawai dan didukung oleh kapasitas organisasi yang memadai, maka penyelenggaraan tata pemerintahan yang baik akan terwujud, sebaliknya kelemahan motivasi dalam bekerja merupakan salah satu sebab keruntuhan kinerja organisasi di Indonesia.

5. Pengaruh Kompensasi terhadap Kinerja

Dari hasil penelitian diketahui bahwa kompensasi mempengaruhi kinerja Pegawai kantor Dishubkominfo Kota Tegal. Kompensasi yang diterima sesuai dengan keadaan yang menyenangkan atau emosi positif yang dihasilkan dari penilaian pekerjaan atau pengalaman kerja seseorang. Kinerja karyawan dapat ditelusuri dari sikap karyawan seperti kompensasi yang diterima setiap pegawai.

\section{Kesimpulan}

Berdasarkan hasil analisis data dan pembahasan yang telah dikemukakan dapat ditarik kesimpulan sebagai berikut:

1. Lingkungan Kerja berpengaruh terhadap Kompensasi pegawai Dishubkominfo Kota Tegal adalah terbukti.

2. Pengawasan berpengaruh terhadap Kompensasi pegawai Dishubkominfo Kota Tegal adalah tidak terbukti.

3. Kompetensi berpengaruh terhadap Kompensasi pegawai Dishubkominfo Kota Tegal adalah terbukti,

4. Motivasi berpengaruh terhadap Kompensasi pegawai Dishubkominfo Kota Tegal adalah tidak terbukti.

5. Lingkungan Kerja berpengaruh terhadap kinerja pegawai Dishubkominfo Kota Tegal adalah terbukti.

6. Pengawasan berpengaruh terhadap kinerja pegawai Dishubkominfo Kota Tegal adalah tidak terbukti.

7. Kompetensi berpengaruh terhadap kinerja pegawai Dishubkominfo Kota Tegal adalah terbukti. 
8. Motivasi berpengaruh terhadap kinerja pegawai Dishubkominfo Kota Tegal adalah terbukti.

9. Kompensasi sebagai variabel intervening mempengaruhi positif antara lingkungan kerja, pengawasan, kompetensi dan motivasi terhadap kinerja pegawai Dishubkominfo Kota Tegal adalah terbukti.

\section{Saran}

Adapun saran yang diberikan untuk menelitian yang akan datang ada sebagai berikut:
1. Penelitian selanjutnya diharapkan menggunakan jenis instansi lain sebagai obyek penelitian.

2. Peneliti selanjutnya diharapkan untuk mengembangkan penelitian ini dengan juga meneliti faktorfaktor lain yang berpengaruh terhadap kinerja pegawai yang tidak diteliti oleh peneliti.

\section{DAFTAR PUSTAKA}

Dessler, Gary, 2009. Manajemen Sumber Daya Manusia. Jakarta: Indeks.

Fathonah, Siti dan Ida Utami. 2012. Pengaruh Kompensasi, Pengembangan Karir, Lingkungan Kerja dan Komitmen Organsiasi terhadap Kepuasan Kerja Pegawai Sekretariat Daerah Kabupaten Karanganyar dengan Keyakinan Diri (self Efficacy) Sebagai Variabel Pemoderasi. Jurnal STIE AUB Surakarta.

Hasibuan, Malayu, S.P., 2012. Manajemen Sumber Daya Manusia. Edisi Revisi. PT. Bumi Aksara. Jakarta.

Prasetya, Irhas Ivandhani. 2015. Pengaruh Disiplin Kerja, Motivasi, Kompensasi Dan Lingkungan Kerja Terhadap Kinerja Pegawai Pada Dinas Pendapatan Dan Pengelolaan Aset Daerah (DPPAD) Provinsi Jawa Tengah. Jurnal. eprints.dinus.ac.id/17291/1/jurnal_16446.pdf

Puspitasari Intan, Endang Siti Rahayu, Arip Wijianto. 2015. Pengaruh Motivasi Dan Lingkungan Kerja Terhadap Kinerja Pegawai Di Pt. Sukoharjo Makmur Abadi. Jurnal. Universitas Sebelas Maret. jurnal.fp.uns.ac.id/index.php/agrista/article/

Sarwono, Jonathan. 2007. Analisis Jalur untuk Riset Bisnis dengan SPSS. Andi Offset. Yogyakarta.

Sugiyono. 2001. Metode Penelitian Bisnis. CV. Alfabeta. Bandung 